\title{
Е.В. Лиханос
}

\section{Специальная библиотека как центр информационно- консультационной поддержки доступного туризма}

Реферат. Сегодня специальными библиотеками России успешно осваивается такое направление деятельности, как поддержка доступного туризма. Однако эта работа носит преимущественно моноаспектный, порой стохастичный характер, часто ограничиваясь туротерапией. Информационно-методическая и библиографическая тематическая поддержка предоставляется значительно реже, почти полностью отсутствует консультативная составляющая.

В статье описан интересный опыт Ставропольской краевой библиотеки для слепых и слабовидящих им. В. Маяковского (СКБСС), на базе которой в 2015 г. было создано структурное подразделение специального назначения - Центр информационно-консультативной поддержки доступного туризма «Инватуринфо» (ЦИКПДТ). Его основная цель - осуществление комплексной информационно-консультативной деятельности по вопросам туризма для лиц с ограниченными возможностями здоровья. Работа Центра имеет полиаспектную направленность и детерминирована. Основные принципы, лежащие в основе деятельности «Инватуринфо»: интегрированность, непрерывность, адаптивность и комплексность. Особенное внимание уделено принципу комплексности, который проявляется в реализуемых ЦИКПДТ функциях и оказываемых услугах. $К$ их числу относятся: исследовательская, информационно-методическая, информационно-библиографическая, консультативная, просветительская, туротерапевтическая. Такая комплексность позволяет наиболее четко и полно встроить деятельность «Инватуринфо» в работу библиотеки в целом, обеспечить согласованность целей различных уровней. В результате ЦИКПДТ рассматривается как когерентная подсистема библиотечной системы, а деятельность СКБСС по доступному туризму как системная.

Ключевые слова: доступный туризм, центр туризма, специальная библиотека, информация, системность, комплексность.

Для цитирования: Лиханос E.B. Специальная библиотека как центр информационно-консультационной поддержки доступного туризма // Библиотековедение. 2017. Т. 66, № 1. С. $102-107$.

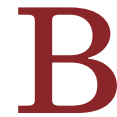
2015 г. в Ставропольском крае начал работу Центр информационно-консультационной поддержки доступного туризма «Инватуринфо» (ЦИКПДТ). Центр был создан как структурное подразделение специального назначения в рамках инновационно-методического отдела Ставропольской краевой библиотеки для слепых и слабовидящих им. В. Маяковского (СКБСС). Этот проект стал главным итогом реализации внутрибиблиотечной программы «Векторы инновационного развития: доступный туризм и специальная библиотека - перспектива в интеграции», рассчитанной на 2013-2015 годы.

Важно отметить, что «Инватуринфо»единственная подобная структура в регионе. Прямых аналогов не существует и на отечественном уровне. Поясним: те или иные аспекты деятельности по доступному туризму достаточно успешно

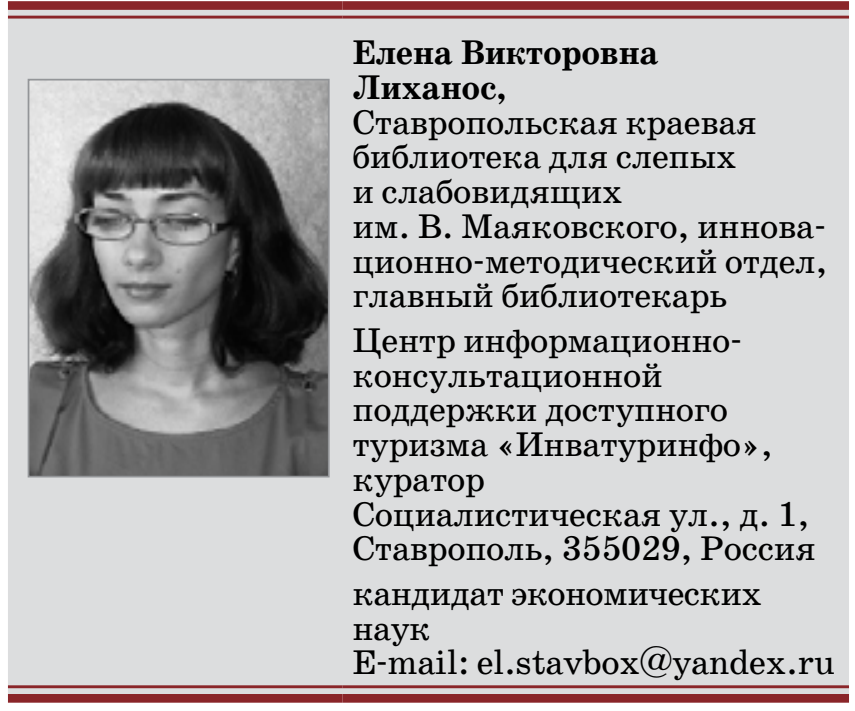


реализуются специальными библиотеками России, о чем свидетельствуют данные всероссийского исследования «Доступный туризм и специальная библиотека» [1], а также экспресс-анализ веб-страниц библиотек для слепых.

Интересен опыт Владимирской областной специальной библиотеки, специалисты которой проводят «живые» экскурсии для своих читателей [2]. Библиотека берет на себя организующую роль, ее сотрудники выступают гидами, не прибегая к помощи профессиональных экскурсоводов. Турмероприятия имеют регулярный характер, частота их проведения определяется пожеланиями заказчика или какой-либо знаменательной датой. На сайте организации создан раздел «Проведение экскурсий», где представлены описания-отчеты совершенных путешествий.

Санкт-Петербургская государственная библиотека для слепых и слабовидящих также активно работает по данному направлению [3]. На ее сайте можно найти ссылку «Путешественникам о Санкт-Петербурге», пройдя по которой пользователь попадает на ресурс (http://otzyv.ru), где собрана информация об экскурсионных маршрутах и достопримечательностях как северной столицы, так и других городов России, отзывы путешественников (не имеющих ограничений по здоровью). Заметим, что развитию доступного туризма в Санкт-Петербурге способствует не только деятельность специальной библиотеки, но и отдельные проектные инициативы, активная работа инватуркомпании «Либерти», занимающейся организацией адаптированных туров для российских и зарубежных туристов-колясочников.

Успешно в своей деятельности экскурсионные средства применяют также специальные библиотеки Краснодара, Курска, Липецка и др., однако на их сайтах этот аспект находит отражение только в новостной информации. Безусловно, по направлению поддержки доступного туризма работает значительно больше российских библиотек для слепых, единицы туркомпаний. Подробный анализ такой работы - тема отдельного материала. В настоящей статье мы привели лишь некоторые примеры, позволяющие говорить о преимущественно моноаспектном, порой стохастичном характере деятельности спецбиблиотек по доступному туризму, ограничении ее туротерапией. Значительно реже предоставляется информационно-методическая и библиографическая тематическая поддержка, почти полностью отсутствует консультативная составляющая, при том что эти функции значительно ближе библиотечному учреждению, чем экскурсионный сервис.

Все чаще информационную поддержку туризма на уровне субъекта Федерации оказывают региональные научные и муниципальные библиотечные учреждения, являясь местом средоточия информации краеведческого характера. Например, Информационный центр культурно-позна- вательного туризма создан на базе Национальной библиотеки Республики Бурятия, в аналогичном направлении работают и библиотеки Липецкой области, интересен опыт Централизованной библиотечной системы Ростова-на-Дону, Иркутской областной государственной универсальной научной библиотеки им. И.И. Молчанова-Сибирского и др. [4-6]. Однако особые информационные потребности рассматриваемой категории путешественников, как правило, не учитываются. Не принимаются во внимание такие потребности и туристско-информационными центрами (ТИЦ), которые достаточно активно функционируют в России. Показателен опыт европейских стран (Bеликобритания, Испания, Италия и др.), где работают ТИЦ, ориентированные на информационную (и не только) поддержку туристов с инвалидностью [7-10]. В частности, они предоставляют информацию относительно доступности того или иного объекта посещения, турмаршрута, страноведческие данные, адаптивную технику, помогают выполнить бронирование и планирование путешествия, оказывают волонтерскую помощь и пр.

Как отмечается в «Стратегии развития туризма в Российской Федерации на период до 2020 г.», одной из проблем «въездного туризма является недостаточно комфортная туристская информационная среда» [11]. Принимая во внимание ратификацию Россией Конвенции ООН о правах инвалидов, такая среда обязательно должна учитывать особые потребности лиц с ограничением по здоровью, в том числе по зрению. Исходя из этого, в число важнейших задач, решение которых необходимо с позиции обеспечения устойчивого функционирования национального турсектора, входят вопросы модернизации его информационной поддержки с учетом ее доступности туристам с инвалидностью.

В связи с этим весьма актуальным и своевременным представляется создание ЦИКПДТ, работа которого имеет полиаспектную направленность и детерминированность.

Основная цель ЦИкПДТ «Инватуринфо» СКБСС - осуществление комплексной информационно-консультативной деятельности по вопросам туризма для лиц с ограниченными возможностями здоровья. «Инватуринфо» ориентирован на работу с различными участниками туристического рынка, включая:

- лиц с инвалидностью и членов их семей;

- специалистов туриндустрии;

- сотрудников библиотек различных типов и видов;

- образовательные учреждения, реализующие подготовку по профильным направлениям.

Деятельность Центра базируется на принципах интегрированности, непрерывности, адаптивности и комплексности. Принцип интегрированности предполагает объединение отдельных элементов в целое. Доступный туризм как один из векторов работы СКБСС имеет тесную взаимосвязь с други- 
ми направлениями деятельности, образуя с ними единое целое. Описываемый принцип имеет организационное, документационное и информационное отражения. Так, организационно «Инватуринфо» призван курировать деятельность библиотеки по исследуемому направлению. При этом в его работе участвуют все структурные подразделения в соответствии с их компетенциями, что закреплено Положением о ЦИКПДТ. Планово-отчетная деятельность «Инватуринфо» включается в планово-отчетную деятельность библиотеки в целом. Таким образом, документационно этот аспект работы имеет не только текущее, но и перспективное закрепление в рамках краткосрочных и стратегических программ развития СКБСС, которые обеспечивают непрерывность функционирования Центра, регулярность оказываемого им сервиса (принцип непрерывности). Иначе говоря, в соответствии с принципом непрерывности обеспечивается бесперебойное функционирование «Инватуринфо», детерминированность его деятельности. Информационно деятельность ЦИКПДТ представлена в разделе «Центр поддержки доступного туризма» на сайте библиотеки. Событийное сопровождение его функционирования ведется в новостном разделе. Таким образом, информация о работе «Инватуринфо» не является дискретной, а включена в общую информацию о СКБСС, связана с ней.

Принцип адаптивности достаточно широко известен, а потому не нуждается в детальной расшифровке. Отметим только, что в нашем случае речь идет об умении трансформировать деятельность Центра не только в соответствии с требованиями внутри- и внешнебиблиотечной среды, но и с учетом изменений, происходящих в сфере туризма и культуры в целом. В противном случае предлагаемый сервис может оказаться невостребованным или неконкурентоспособным.

Принцип комплексности мы понимаем как необходимость полиаспектного развития ЦИКПДТ, при котором отдельному аспекту соответствует одна или несколько функций (направлений, элементов). Полиаспектность позволяет наиболее полно удовлетворять информационные потребности туристов с инвалидностью и других участников туристического рынка. Каждый аспект работы Центра вносит свой вклад в достижение его основной цели и цели СКБСС, связанной с обеспечением лицам с ограниченными возможностями здоровья безбарьерного доступа к информации. При этом важно понимать, что информация (в рассматриваемой ситуации туристская) может носить общий и специальный характер, ориентируясь, в первом случае, на туриста вообще, во втором - на туриста с особыми потребностями. В связи с соответствием целевых установок различных уровней можно говорить о когерентности ЦИКПДТ как подсистемы библиотечной системы.

Комплексность работы «Инватуринфо» проявляется в реализуемых им функциях и оказы- ваемых услугах, определяемых Положением о Центре. К основным функциям ЦИКПДТ относятся [12]:

- исследовательская работа;

- разработка информационно-методических материалов по различным аспектам туризма и инватуризма;

- тематическое информационно-библиографическое обслуживание;

- оказание информационно-консультационного сервиса по вопросам доступного туризма;

- просветительская деятельность;

- реализация мероприятий туротерапевтического характера и др.

Одним из основополагающих направлений работы «Инватуринфо» является исследовательское. В 2015 г. Центром было проведено всероссийское исследование «Доступный туризм и специальная библиотека» [1], ставшее первой масштабной работой подобной тематики, которая позволила определить степень актуальности развития доступного туризма как направления деятельности специальной библиотеки, выявить наиболее и наименее освоенные аспекты такой деятельности, потребность в информационно-методических разработках. Данный опыт тематической исследовательской работы был замечен и взят на вооружение коллегами из специальных библиотек России. В частности, Свердловская областная специальная библиотека для слепых в 2016 г. провела региональное исследование «Доступный туризм и муниципальная библиотека» [13].

Данные [1], а также мониторинг мнений читателей и библиотечных специалистов способствовали актуализации тематической информационно-методической работы. Регулярно разрабатываются и выпускаются издания из серии «Мир без границ», посвященной различным аспектам инватурпроблематики. В материалах цикла раскрываются вопросы туристского страноведения, описывается практика организации безбарьерной туристической среды в России и за рубежом. Кроме того, приводится опыт путешествия туристов с той или иной формой инвалидности, рассматриваются вопросы документационного обеспечения поездки и др. На сегодняшний день серия насчитывает 10 выпусков, которые могут служить не только основой для проведения мероприятий в форме виртуальной экскурсии, но и предлагаться для самостоятельного знакомства с ними читателей. Все выпуски «Мира без границ» издаются укрупненным шрифтом, а некоторые в озвученном и рельефно-точечном вариантах.

В свою очередь, информационно-методическая деятельность служит одним из базисов оказания тематического консультационного сервиса. За первый год работы специалистами «Инватуринфо» были выполнены десятки устных и письменных заявок на консультирование, 
инициаторами которых стали как физические (читатели СКБСС, члены различных городских и региональных организаций инвалидов и пр.), так и юридические лица (турфирмы края, спецбиблиотеки России и др.). Тематика их различна: от вопросов по организации работы в рамках доступного туризма, выяснения температурно-климатического режима и особенностей пребывания в той или иной стране до установления уровня доступности конкретной дестинации или средства размещения и др. Имели место и запросы, связанные с защитой туристских прав путешественника с инвалидностью.

В обеспечении качества и оперативности консультационной работы Центра большое значение имеет реализация еще одного направления деятельности - информационно-библиографического. На сайте СКБСС (http://www.skbs.ru/) в разделе «Центр поддержки доступного туризма» представлена контактная информация, перечень и порядок предоставления услуг, сведения о российских компаниях, занимающихся вопросами туризма для лиц с инвалидностью. Кроме того, раздел содержит библиографический список тематических статей, перечень собственных разработок библиотеки по вопросам инватурпроблематики, ссылки на полезные ресурсы.

Активно развиваются партнерские связи. Взаимовыгодные отношения устанавливаются на различных уровнях и в различных областях. В частности, надежными партнерами библиотеки стали турфирмы края, музейные учреждения, региональные организации инвалидов (глухих, слепых и др.), библиотечные учреждения (муниципальные и специальные) и др. Деятельность СКБСС по доступному туризму поддерживают краевые министерства культуры, труда и социальной защиты населения. Ведется работа по укреплению контактов с зарубежными партнерами.

Реализация Центром описанных функций была бы невозможна без просвещенческого компонента, отражающего миссию «Инватуринфо» . Просветительская деятельность направлена на различных участников туристического рынка, в зависимости от этого меняются ее цели, методы и формы. Так, применительно к туристам с ограниченными возможностями здоровья в качестве цели выступает развитие их туристской культуры, стимулирование к активному познанию природных и историко-культурных богатств. Для этой категории реализуются мероприятия, посвященные различным аспектам инватурпроблематики. Как уже отмечалось, основой для их проведения являются результаты информационно-методической деятельности, отраженной, в том числе, и в изданиях серии «Мир без границ» .

Другое средство стимулирования - туротерапия. Путешествия (виртуальные и, прежде все- го, реальные) крайне востребованы инватуристами Ставрополья. Нами применяются различные механизмы организации таких поездок, один из них - в рамках социального проекта. В настоящее время реализуется уже третья проектная программа «Повышение качества жизни людей с инвалидностью и пожилых как приоритет цивилизованного общества и государства», подготовленная совместно с городской общественной организацией инвалидов «Помощь». Были подведены итоги командного партнерского проекта СКБСС и ставропольской краевой общественной организации Всероссийского общества слепых «Трогательный мир», несколькими годами ранее был осуществлен проект «За гранью повседневности». В рамках этих проектов сотни читателей библиотеки смогли совершить турпоездки по различным уголкам Ставрополья и за его пределы, познакомиться с природными и культурно-историческими достопримечательностями Северного Кавказа. При этом туротерапия выступает не только как инструмент стимулирования к активной познавательной деятельности, развития туристской культуры, но и как средство социокультурной реабилитации инвапутешественников.

Одно из направлений просветительской работы ЦИКПДТ ориентировано на специалистов турсферы. Целью его является повышение информированности участников рынка относительно особых потребностей инватуристов, специфики турсервиса. Одна из форм реализации этой работы выражается в регулярно проводимой информационно-рекламной кампании по продвижению Центра. В частности, были разработаны и распространены памятка «Туризм без барьеров или путешествовать имеет право каждый», информационная листовка ЦИКПДТ. В перспективе планируется организация тематических встреч для представителей туриндустрии.

Таким образом, базисным элементом деятельности «Инватуринфо» выступает исследовательский. Он позволяет актуализировать информационно-методическую и информационнобиблиографическую работу. Первая, в свою очередь, служит основой просветительской и туротерапевтической деятельности, а вместе со второй они формируют фундамент консультационного сервиса. При этом повышению качества и оперативности работы по отмеченным направлениям способствует развитие партнерских отношений СКБСС. Установление связей между описанными компонентами деятельности «Инватуринфо» способствует эффективности его функционирования, а построение новых позволит расширить спектр реализуемых работ и услуг.

Все изложенное дает возможность рассматривать деятельность СКБСС по доступному туризму как системную, а функционирование ЦИКПДТ как комплексное. 


\section{Список источников}

1. Лиханос E.B. Доступный туризм и специальная библиотека : итоги всероссийского исследования // Библиотековедение. 2015. № 4. С. 110-113.

2. Владимирская областная специальная библиотека для слепых [Электронный ресурс]. URL: http:// www.vsbs.ru/ (дата обращения: 01.10.2016).

3. Санкт-Петербургская государственная библиотека для слепых и слабовидящих [Электронный ресурс]. URL: http://gbs.spb.ru/ (дата обращения: 01.10.2016).

4. Библиотеки как информационные центры культурного и экологического туризма [Электронный pecypc]. URL: http://book.uraic.ru/files/metod/obzor/ biblioteki_i_turizm.htm (дата обращения: 29.08.2016).

5. Библиотечное краеведение как ресурс развития внутреннего туризма в Иркутской области [Электронный ресурc]. URL: http://www.cultmanager. $\mathrm{ru} /$ article/5092-oblastnoy-proekt-bibliotechnoekraevedenie-kak-resurs-razvitiya-vnutrennegoturizma-v (дата обращения: 10.09.2016).

6. Доступный туризм и муниципальная библиотека [Электронный ресурc]. URL: http://sosbs.ru/ kollegam/issledovaniya/2016_god._issledovanie_ dostupnyy_turizm_i_municipalnaya_bibli/ (дата обращения: 01.10.2016).

7. Accessible Italy: Disability Travel [Электронный pecypc]. URL: http://www.accessibleitaly.com/ (дата обращения: 10.10.2016).
8. Accessible Tourism in Spain [Электронный ресурс]. URL: http://www.spain.info/en_US/informacionpractica/turismo-accesible/ (дата обращения: 08.10.2016).

9. Tourism for All [Электронный pecypc]. URL: https://www.tourismforall.org.uk (дата обращения: 05.10.2016).

10. Visit London for the First Time [Электронный pecypc]. URL: http://www.visitlondon.com/discoverlondon/ (дата обращения: 05.10.2016).

11. Стратегия развития туризма в Российской Федерации на период до 2020 г. [Электронный ресурс]. URL: http://www.rg.ru/2014/06/09/turizm-sitedok.html (дата обращения: 30.08.2016).

12. Лиханос E.B. Об аспектах работы специальной библиотеки по направлению «Доступный туризм» // Шестнадцатые Кайгородовские чтения. Культура, наука, образование в информационном пространстве региона : сб. материалов Всерос. науч.-практ. конф. Краснодар : КГИК, 2016. Вып. 16. С. $60-62$.

13. Краеведческий туризм как перспективное направление библиотечной деятельности [Электронный pecypc]. URL: http://www.donlib.ru/ professionalnye-smi/2013/11/11/kraevedcheskijturizm-kak-perspektivnoe-napravlenie-bibliotechnojdeyatelnosti.html (дата обращения: 10.09.2016).

\title{
Special Library as an Information and Advisory Support Center of Accessible Tourism
}

\section{Elena V. Likhanos,}

The Stavropol Regional Library for the Blind and Visually Impaired named after V. Mayakovsky, 1 Sotsialistitcheskaya Str., Stavropol, 355029, Russia

E-mail: el.stavbox@yandex.ru

\begin{abstract}
Today special libraries of Russia successfully master such area of activity as support of accessible tourism. However, this work has mainly mono-aspectual character, sometimes stochastic in nature, often is limited to tour-therapy. Informational-methodical and bibliographic thematic support is provided much less, and is almost missing the consultative component.

The article describes an interesting experience of the Stavropol Regional Library for the Blind and Visually Impaired named after Vladimir Mayakovsky; on its basis in 2015 there was established the special-purpose structural division - Information and Advisory Support Center of Accessible Tourism "Invatourinfo". The main goal of the Center is implementation of comprehensive informational and advisory activities in the area of tourism for the people with disabilities. The work of the Centre has poly-aspectual and algoristic character. The main principles underlying the activities of "Invatourinfo" are: integrity, continuity, adaptability and comprehensiveness. Special attention is paid to the principle of comprehensiveness, which is manifested in the ongoing functions and services of the Center, which include: research, informational and methodical, informational and bibliographic, advisory, educational, and tour-therapeutic services. This integrated approach allows to more clearly and fully incorporate the activities of "Invatourinfo" in the work of the library as a whole, and to ensure the coherence of goals of different levels. As a result, the Center is regarded as a coherent subsystem of the library system, and the activities of the Center on accessible tourism - as systemic.
\end{abstract}


Key words: Accessible Tourism, Center of Tourism, Special Library, Information, Systemacity, Comprehensiveness.

Citation: Likhanos E.V. Special Library as an Information and Advisory Support Center of Accessible Tourism, Bibliotekovedenie [Library and Information Science], 2017, vol. 66, no. 1, pp. 102-107.

\section{References}

1. Likhanos E.V. Dostupnyi turizm i spetsial'naya biblioteka: itogi vserossiiskogo issledovaniya [Accessible Tourism and Special Library: the Results of All-Russian Research], Bibliotekovedenie [Library and Information Science], 2015, no. 4, pp. 110-113.

2. Vladimirskaya oblastnaya spetsial'naya biblioteka dlya slepykh [The Vladimir Regional Special Library for the Blind]. Available at: http://www.vsbs.ru/ (accessed 01.10.2016).

3. Sankt-Peterburgskaya gosudarstvennaya biblioteka dlya slepykh i slabovidyashchikh [The St. Petersburg State Library for the Blind and Visually Impaired]. Available at: http://gbs.spb.ru/ (accessed 01.10.2016).

4. Biblioteki kak informatsionnye tsentry kul'turnogo i ekologicheskogo turizma [Libraries as Information Centers of Cultural and Ecological Tourism]. Available at: http://book.uraic.ru/files/metod/obzor/ biblioteki_i_turizm.htm (accessed 29.08.2016).

5. Bibliotechnoe kraevedenie kak resurs razvitiya vnutrennego turizma $v$ Irkutskoi oblasti [Library Local History as a Resource for the Development of Domestic Tourism in the Irkutsk Region]. Available at: http:// www.cultmanager.ru/article/5092-oblastnoy-proektbibliotechnoe-kraevedenie-kak-resurs-razvitiyavnutrennego-turizma-v (accessed 10.09.2016).

6. Dostupnyi turizm i munitsipal'naya biblioteka [Accessible Tourism and the Municipal Library]. Available at: http://sosbs.ru/kollegam/issledovaniya/ 2016_god._issledovanie_dostupnyy_turizm_i_ municipalnaya_bibli/ (accessed 01.10.2016).

7. Accessible Italy: Disability Travel. Available at: http:// www.accessibleitaly.com/ (accessed 10.10.2016).
8. Accessible Tourism in Spain. Available at: http:// www.spain.info/en_US/informacion-practica/ turismo-accesible/ (accessed 08.10.2016).

9. Tourism for All. Available at: https://www. tourismforall.org.uk (accessed 05.10.2016).

10. Visit London for the First Time. Available at: http:// www.visitlondon.com/discover-london/ (accessed 05.10.2016).

11. Strategiya razvitiya turizma $v$ Rossiiskoi Federatsii na period do $2020 \mathrm{~g}$. [The Strategy of Tourism Development in the Russian Federation for the Period till 2020]. Available at: http://www. rg.ru/2014/06/09/turizm-site-dok.html (accessed 30.08.2016).

12. Likhanos E.V. Ob aspektakh raboty spetsial'noi biblioteki po napravleniyu "Dostupnyi turizm" [On Some Aspects of the Special Library Work in the Area of "Accessible Tourism"], Shestnadtsatye Kaigorodovskie chteniya. Kul'tura, nauka, obrazovanie $v$ informatsionnom prostranstve regiona: sb. materialov Vseros. nauch.-prakt. konf. [Proc. of the All-Rus. Sci.Prac. Conf. "The Sixteenth Kaigorodov Readings. Culture, Science, Education in the Information Space of the Region"]. Krasnodar, KGIK Publ., 2016, issue 16, pp. 60-62.

13. Kraevedcheskii turizm kak perspektivnoe napravlenie bibliotechnoi deyatel'nosti [Local Lore Tourism as a Perspective Direction of Library Activity]. Available at: http://www.donlib.ru/ professionalnye-smi/2013/11/11/kraevedcheskijturizm-kak-perspektivnoe-napravlenie-bibliotechnojdeyatelnosti.html (accessed 10.09.2016). 